\title{
Influence of salt on drying performance of silver jewfish (Otolithes argentatus) in a Hohenheim type solar tunnel dryer
}

\author{
K. B. Uddin ${ }^{1}$, M. S. Reza ${ }^{2^{*}}$, M. N. Islam ${ }^{2}$ and M. Kamal ${ }^{2}$ \\ ${ }^{1}$ Riverine Sub-Station, Bangladesh Fisheries Research Institute, Rangamati-4500 and ${ }^{2}$ Department of Fisheries \\ Technology, Bangladesh Agricultural University, Mymensingh-2202, Bangladesh, *E-mail: rezams@gmail.com
}

\begin{abstract}
Studies were conducted to investigate the influence of salt treatment on the drying performance of commercially important marine fish, silver jewfish (Otolithes argentatus) in a Hohenheim-type solar tunnel dryer. Different brine concentrations viz., $0 \%, 10 \%, 15 \%, 20 \%$ and $25 \%$ were used, where fish were treated for $12 \mathrm{hr}$ after sorting, grading, dressing and washing. Temperature inside the dryer varied from 36 to $55^{\circ} \mathrm{C}$ with an average air velocity of $1.5 \mathrm{~m} / \mathrm{s}$. Moisture content of fish was reduced to $16 \%$ and it was found that the use of salt in silver jewfish significantly reduced the drying period in solar tunnel dryer to $34 \mathrm{hr}$ compared to those of $40 \mathrm{hr}$ for control fish. Moisture content of $10 \%$ salt treated sample decreased rapidly compared to other salt treated samples where moisture content reduced to below $16 \%$ within $34 \mathrm{hr}$. This indicates that addition of salt in raw material reduced drying time as well as improves the quality of the final product.
\end{abstract}

Keywords: Silver jewfish, Salting, Solar tunnel dryer, Drying performance

\section{Introduction}

Silver jewfish (Otolithes argentatus), also known as silver croaker, is one of the most commercially important marine fish species in Bangladesh harvested from the Bay of Bengal which is used for natural sun drying as well as for production of salted-dehydrated products for export purposes. There are number of jewfish species available in the Bay of Bengal almost round the year. Every year a large amount of silver jewfish are harvested from coastal and marine waters where larger sized fishes are used for valueadded products and small sized are used for natural sun drying. Jewfish are caught both by the industrial and artisanal fisheries where the total production stood to $38,414 \mathrm{mt}$ in 2008-2009 (FRSS, 2010) which is $7.46 \%$ of the total marine catch of the country. It was reported that some $86 \%$ of the total jewfish catch are dried and mainly exported to China, Hong Kong, Singapore, South Korea, Japan and other Southeast Asian countries (Alam, 2012). In 2008-09 financial year, Bangladesh exported $425 \mathrm{mt}$ of dry fish which was worth US\$ 0.199 million and currently shows an increasing demand and trend due to larger size of the jewfish itself and better quality (DoF, 2013).

Drying has long been one the most popular method of fish processing throughout the world including Bangladesh due to its simplicity and versatility. The method has the benefit where the nutritional quality of the fish remains almost intact (as per unit weight) and possesses a special flavour which is highly appreciated by different ethnic people. Both natural sun drying and dehydration methods are used to produce dry fish, but for export market dehydration method using specially designed dryers are used. Natural drying in the sun is not satisfactory due to contamination by blowfly and insect infestation. The process is not hygienic where fish remains vulnerable to infestation with blow fly larva and beetle attack. To avoid this infestation and for safe storage, farmers often apply insecticides including DDT in fish (Bala and Mondol, 1992). These fish treated with insecticides create broad spectrum environmental and health hazards. To minimize these problems, in Cox's Bazar, Chittagone and other coastal districts of Bangladesh, several large drying yards was established where they produce salted-dehydrated silver jewfish under strict supervision of the buyers themselves.

Salted-dehydrated fish is usually produced where a pre-treatment of salt is done in the fish during sundrying. Small amount of salt makes the texture compact, reduces the effects of contamination, destroys some of the bacteria and helps release water from the fish so that drying becomes easier and quick (Alam, 2012). Sodium chloride has traditionally been used in curing and preservation of meat and fish due 
to its capacity to improve the water holding capacity of proteins. While Kiaye (2004) stated that brining reduces the microorganisms count on dry fish, studies by Oliviera et al. (2006) and Graivier et al. (2006) indicated that concentrations of salt used in osmotic dehydration in excess of $5 \%$ are beyond the permissible levels for human consumption, a salt treatment of $2-3 \%$ is, therefore, used to prepare good quality salted-dehydrated jewfish product. The processing treatment used in the coastal districts for export purpose mostly rely on natural weather condition where maturation time of salted fish and subsequent drying of the salted products are conducted under the open sky. There has been, however, a report that an unknown powdered chemical which might be an insecticide (local processors call it 'medicine') is used at a rate of $1 \mathrm{~g} / 10 \mathrm{~L}$ water to prevent the attack by blow fly, Dermestes beetle and mites infestations as well as microbial contaminations (Alam, 2012). This is an indication that contamination of the product occurred in the process line from the environment as no protection is taken to prevent insect infestation.

Solar tunnel dryer may be used as an alternative to traditional sun drying to produce quality dried products and to reduce the post-harvest losses. Solar dryers employ some means of collecting and concentrating solar radiations to achieve elevated temperatures and reduced relative humidity during drying. The available information suggests that solar tunnel dryer are effective in controlling insect infestation, spoilage, contaminants and having higher drying rate over the traditional sun drying for producing high quality products with longer shelf-life. The solar tunnel dryer developed by Hohenheim University (Germany), has been successfully used for drying in the Southeast Asian region (University of Hohenheim, 1995). In a previous study, a Hohnenheim type solar tunnel dryer constructed with locally available materials was found very suitable for drying of silver jewfish at temperature of $35^{\circ} \mathrm{C}$ to $52^{\circ} \mathrm{C}$ for 5 days without showing any infestation, oxidative rancidity, spoilage and contamination (Bala and Hossain, 1998; Bala and Mondol, 2001; Reza et al., 2009). However, there is little or no work done in the past in Bangladesh on the influence of salt on the drying performance in solar tunnel dryer and quality changes during storage conditions. In view of the above facts, the proposed study has been designed to investigate the influence of salt on drying performance of silver jewfish in a solar tunnel dryer.

\section{Materials and Methods}

Fish: Silver jewfish (Otolithes argentatus) were purchased directly from the BFDC landing centre, Cox's Bazar and were transported to the laboratory of Department of Fisheries Technology, Bangladesh Agricultural University, Mymensingh, in an insulated box with ice (1:1). Average length of the 10 randomly sampled fish was $15.22 \mathrm{~cm}$. Average weights of the 10 randomly taken fishes before and after gutting was $318.16 \mathrm{~g}$ and $190.20 \mathrm{~g}$, respectively.

Solar tunnel dryer: A Hohenheim-type solar tunnel dryer was used for drying marine fish which was constructed using locally available materials and the size of the dryer was $20 \mathrm{~m} \times 2 \mathrm{~m}$ with $20 \mathrm{~m}^{2}$ drying area. The solar tunnel dryer consists of a flat plate air-heating collector, a tunnel-drying unit and four small fans to provide the required airflow over the product to be dried. Both the collector and the drying unit are covered with transparent polythene sheet. Black paint is used as heat absorber in the collector. The products to be dried are placed in a thin layer on a bamboo made mat in the tunnel dryer. The whole system is placed horizontally on a raised platform. The air at required rate is provided by four DC fans operated by two photovoltaic modules as the air is passed over the products. The black painted collector absorbs heat through transparent polythene from sunlight. The air from the fans blows over the collector and then heated air passes over the products. Solar radiation also passes through the transparent cover of the dryer and heats the products in the dryer. This enhances the drying rate and the temperature in the dryer rises in the range of $36^{\circ}$ to $55^{\circ} \mathrm{C}$.

Processing techniques for production of dried fish in solar tunnel dryer: Fresh marine fish silver jewfish were graded according to size. The graded fishes were then washed with tap water to remove any kind of undesirable materials attached with the fish body. Fishes were simply gutted by using knives and scissors and the entire viscera were removed. After gutting, the raw materials were washed again with tap water to remove blood, slime and other undesirable substances. After thoroughly washed the raw materials were split longitudinally and soaked $12 \mathrm{hr}$ in different salt concentration $(10,15,20$ and $25 \%$ ). 
After overnight salt treatment the fishes were then dried in solar tunnel. The drying time was 34 to 38 hours in solar tunnel dyer. The dried fishes were then graded according to size, broken products or any other abnormalities. After drying, the processed products were packed in polyethylene bag using sealer to prevent moisture absorption. Processing steps for production of solar tunnel dried silver jewfish products are shown in Fig. 1.

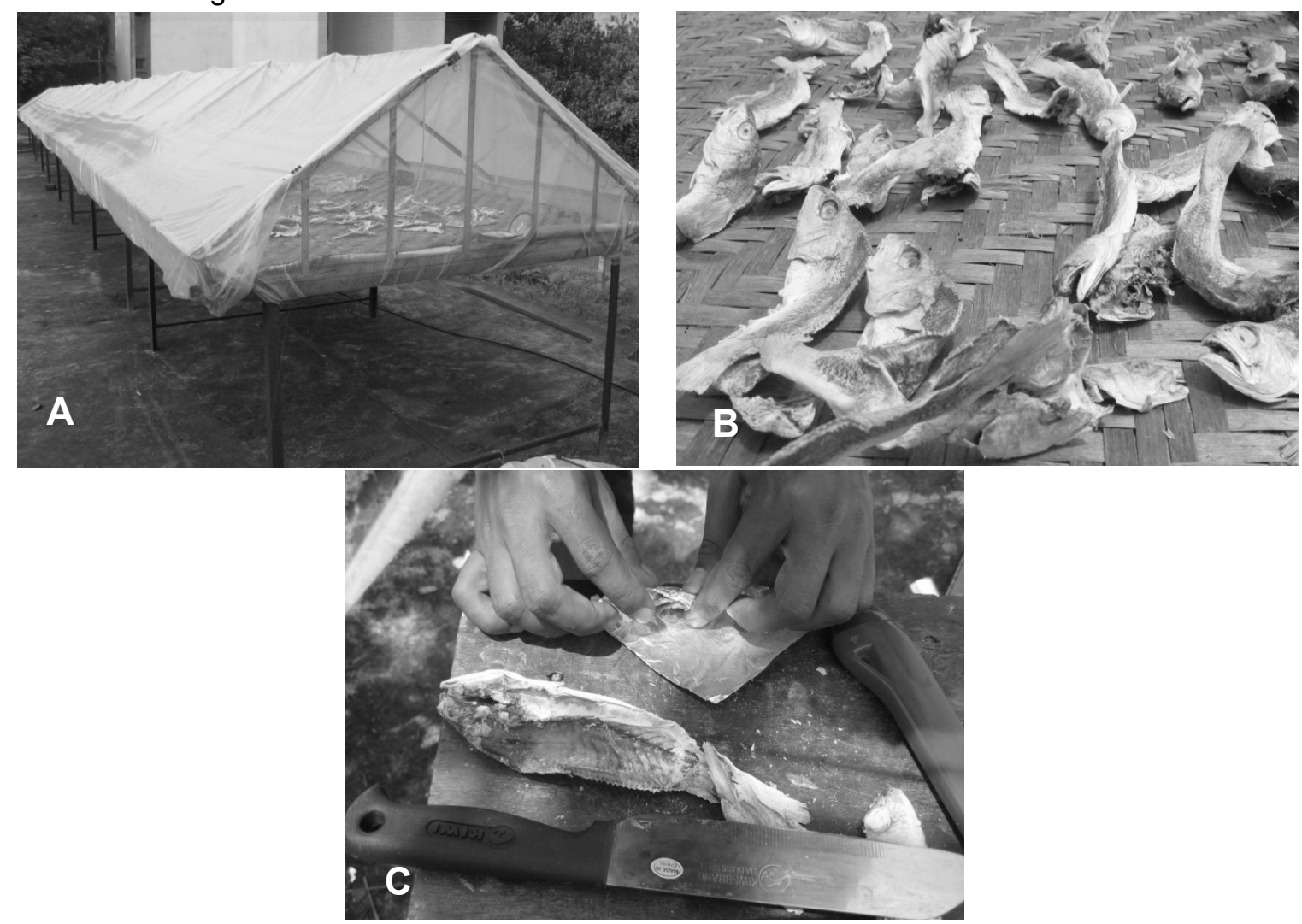

Fig. 1. Processing steps for production of solar tunnel dried silver jewfish products, (a) solar tunnel dryer used, (b) dried product and (c) sample collection for analysis

\section{Measurement of temperature and humidity inside solar tunnel dryer}

Air temperature inside and outside of solar tunnel dryer at various locations was measured by using thermometers. The relative humidity inside and outside of the dryers was also measured at various locations using relative humidity meter recorded by a data logger. Temperature and humidity data of solar tunnel dryer during drying of fish samples were collected every $2 \mathrm{hr}$ interval. Drying of the silver jewfish in solar tunnel dryer was done according to the processing techniques described in the Fig. 1. The drying process in solar tunnel dryer under direct sunlight started at 8.30 a.m. and continued up to 4.30 p.m. Then the samples of the dryer were collected and kept in air tight condition in polyethylene bags in refrigerator. Next morning samples were again dried until desired moisture content was obtained. Samples were collected every 2 hour interval from solar tunnel dryer to measure the moisture content.

\section{Determination of moisture content of dried fish}

Three pieces of fish were used to evaluate the initial moisture content of the fish by the oven dry method. After brining, three pieces of fish from each treatment were used to determine the moisture content before solar drying. During solar drying samples were collected every two hours interval. Moisture content was determined by placing an accurately weighed known amount of ground sample $(2-5 \mathrm{~g})$ in a pre-weighed porcelain crucible in thermostat oven (Gallenkamp, HOTBOX, Model OVB-306) at $105^{\circ} \mathrm{C}$ for about $24 \mathrm{hrs}$ until constant weight was obtained. The sample was removed from the oven, and cooled in a desiccator, after which its dry weight recorded. The loss of moisture was calculated as percent moisture. 


\section{Sensory analysis of dried products}

For sensory analysis of dried silver jewfish, a trained panel of six judges was formed where scoring was conducted following 9-point hedonic scales. The average score of 5 was considered to be the borderline of acceptability according to Poryan and Pilgrim (1957). The 9-point hedonic scales were as follows: 9. Like extremely, 8 . Like very much, 7. Like moderately, 6. Like slightly, 5. Neither like nor dislike, 4. Dislike slightly, 3. Dislike moderately, 2. Dislike very much, 1 . Dislike extremely.

\section{Statistical analysis}

For the statistical analysis of data Tukey's Test was performed using the SPSS (Statistical Package for Social Science, version 12.0, Chicago, USA).

\section{Results and Discussion}

\section{Changes in temperature and humidity in solar tunnel dryer}

Changing pattern of temperature and relative humidity outside and inside the tunnel of solar dryer are shown in Fig. 2. Outside the tunnel, temperature varied from $29-35^{\circ} \mathrm{C}$ and humidity varied from $47-64 \%$ whereas inside the tunnel, fluctuation of temperature was high with minimum of $36^{\circ} \mathrm{C}$ and maximum of $60^{\circ} \mathrm{C}$. Relative humidity ranged also from $27 \%$ to $60 \%$, with higher in the afternoon and lower in the morning. There was an inverse relationship between temperature and humidity, where relative humidity was low at higher temperature and humidity was high with the lowering of temperature. The relative humidity inside the tunnel was lower compared to outside the tunnel which accelerated the faster drying rate by absorbing higher amount of water from the fish body.
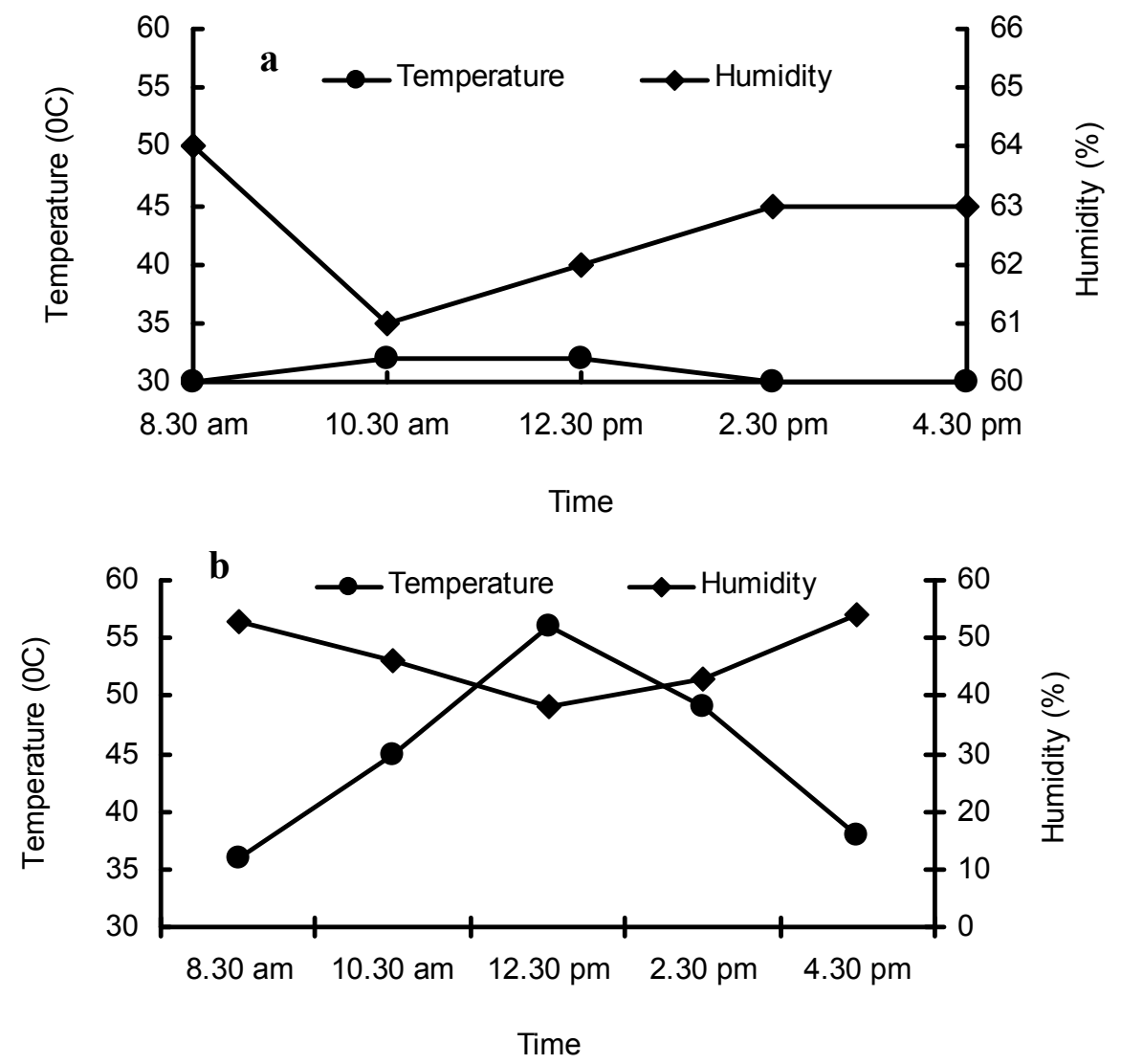

Fig. 2. Relationship between temperature and humidity (a) outside and (b) inside the tunnel with time while drying 


\section{Relation between moisture content of silver jewfish and brine concentration during osmotic dehydration}

The relationship between the moisture content of silver jewfish and brine concentration after osmotic dehydration overnight (i.e.12 hr) is presented in Fig 3. The figure shows that as the brine concentration increased, the amount of moisture content decreased almost linearly. This can be explained by the fact that since salt is hygroscopic, increase in salt concentration increases the amount of salt particles for absorbing water molecules from the fish samples (Graivier et al. 2006).

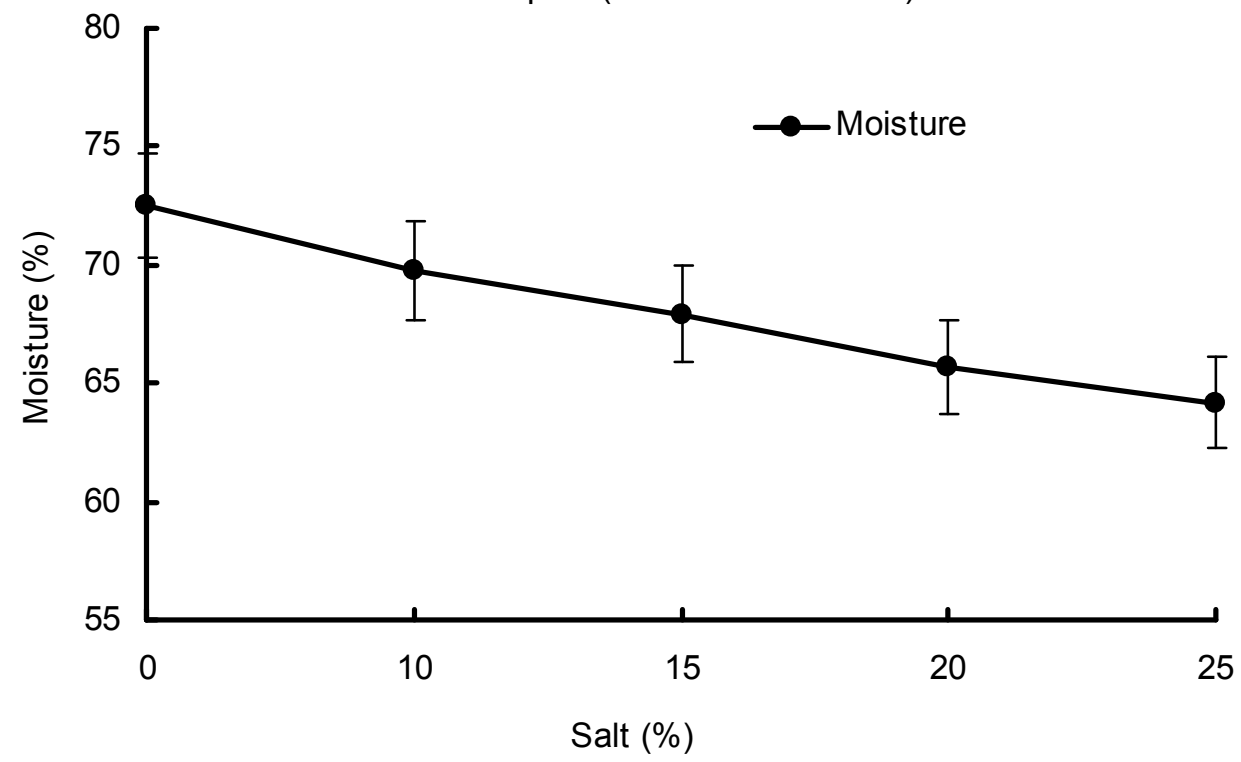

Fig. 3. Relationship between moisture content of silver jewfish and brine concentration during osmotic dehydration

\section{Moisture reduction pattern in solar tunnel dryer}

Changes in moisture content with time interval during drying in solar tunnel dryer has been presented in Fig. 4. Inside the tunnel, temperature was low in the first half of the day where the temperature raised gradually until 3.00 p.m. and remained higher compared to the outside temperature and that higher temperature obviously accelerated drying performance. It was revealed that the moisture content of the fish samples declined very slowly during the first $4 \mathrm{hr}$ of drying. Then the moisture content declined rapidly until last 4 to $6 \mathrm{hr}$ which is a phenomena related to the fact that when the moisture of the fish was high, the air temperature decreased along the length of the drying tunnel and due to the evaporative cooling on the surface of the product, the air temperature in the dryer dropped, resulting is reduced drying rate. Similar incident was also reported by Hossain and Bala (2007) where they dried chilli using similar type of solar tunnel dryer. This stage of initial drying was completed during the first couple of hours and then drying was conducted in a higher rate during the later stages.

In the present study, it was observed that moisture content of $10 \%$ salt treated samples decreased rapidly compared to other salt treated samples and moisture content reached below $16 \%$ within $34 \mathrm{hrs}$ of drying. As for samples treated with $15 \%, 20 \%$ and $25 \%$ salt, their moisture content also reached to $16 \%$ and took approximately a little longer drying period. Not significant difference was found in the drying period among different treatments. In control samples (i.e. without salt), on the other hand, it took more time for drying where the moisture content reached to $18.56 \%$ after $38 \mathrm{hrs}$ of drying and $17.2 \%$ in $40 \mathrm{hrs}$. High temperature and low humidity inside the tunnel accelerated drying compared to open air drying. In general in solar tunnel dryer the samples take drying period of 34-38 hr for drying and reducing the moisture level to below $16 \%$ in all the fish samples (Reza et al. 2009). In solar tunnel dryer, salt treated silver jewfish required more than $30 \mathrm{hr}$ to dry. The reason of longer drying period might be associated 
with the formation of salt-protein crust on the surface of the fish during drying. Del Valle and Nickerson (1968) reported that there is a possibility of forming such crust on the fish surface when drying intensities is comparatively higher, which ultimately inhibited drying. Enhanced drying period might also be associated with the nature of constituent of the fish. The fat content of silver jewfish was higher than other species which probably prevented the drying process and took longer time for drying. Thickness of skin and muscle may be another reason, which prevented the quick evaporation of moisture from fish body (Sultana, 2008).

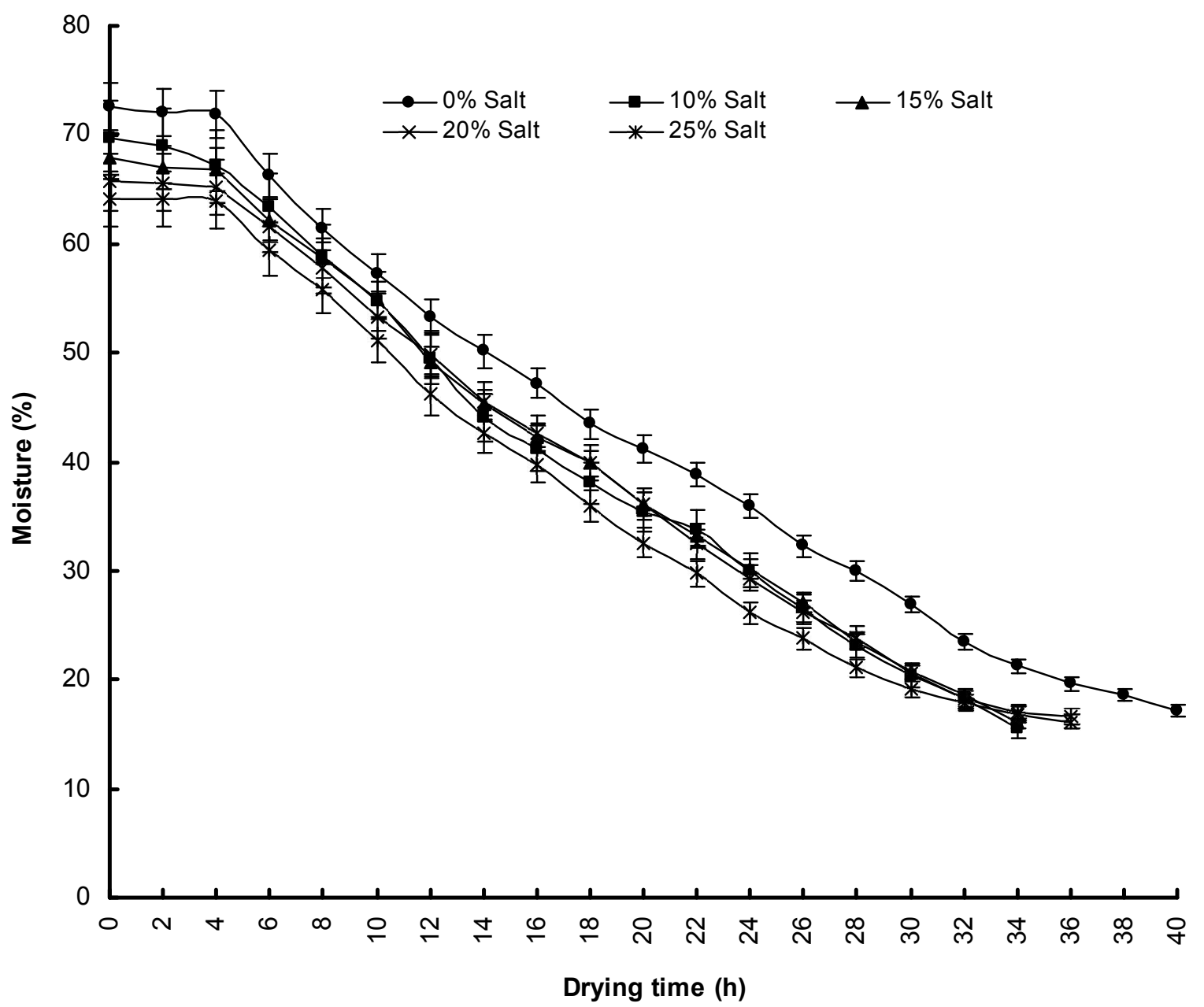

Fig. 4. Changes in moisture content with time interval during drying in solar tunnel dryer

The present study revealed that the application of salt was quite effective in reducing the drying time of silver jewfish samples, and produced good quality dried products with higher sensory score. Although shelf life study of this product was not conducted, it may be predicted that the product would have better shelf life compared to control samples with no salt treatment. In addition to shelf life analysis, further studies may be conducted by using salt concentration lower than $10 \%$ as it may give better result than the results obtained in the present study.

\section{Conclusion}

Silver jewfish is a commercially important marine species and production of good quality dried product was produced using solar tunnel dryer. The study revealed that moisture content of $10 \%$ salt treated samples decreased rapidly compared to others samples reducing the overall drying time and product of improved quality. This method can be used to produce good quality dried product for domestic consumption as well as export market. 
Uddin et al.

\section{References}

Alam, A.K.M.N. 2012. Post-harvest and Trade: Prevailing technology, barriers and domestic marketing scenario in Bangladesh. Proc. National Strategic Workshop on Governance of Marine Small-scale Fisheries in Bangladesh. 29-30 April 2012, Dhaka. MoFL \& BOBP-IGO.

Bala, B.K. and Hossain, M.D. 1998. Experimental investigation of solar drying of fish using tunnel dryer. WREC, Elsevier Science Ltd., 2049-2052 pp.

Bala, B.K. and Mondol, M.R.A. 2001. Experimental investigation of solar drying of fish using tunnel dryer. Drying Technology, 19(2):1-10.

DoF. 2013. Fish fortnight publication, 2013. Published by the Department of Fisheries, Ministry of Fisheries and Livestock, p. 72.

FRSS. 2010. Fisheries Resources Survey System, Department of Fisheries, Ministry of Fisheries and Livestock, the Government of Peoples' Republic of Bangladesh. pp. 48.

Graivier, N., Pinotti, A., Califona, A. and Zaritzky, N. 2006. Diffusion of Sodium Chloride in Fork Tissue, Journal of Food Engineering, 77(4): 910-918.

Hasan, M.M. 2006. Improvement of food quality of traditional dried small indigenous fish products using rotary dryer and solar tunnel dryer. MS Thesis, Department of Fisheries Technology, Bangladesh Agricultural University, Mymensingh, Bangladesh. $126 \mathrm{pp}$.

Hossain, M.A., Bala, B.K. 2007. Drying of hot chilli using solar tunnel drier. Solar Energy 81(1): 85-92.

Kiaye (2004). Effect of improved processing techniques on the quality and storage stability of tilapia from Lake Victoria in Kenya. MSc Thesis, Jomo Kenyatta University, University of Agriculture and Technology, Juja, Kenya.

Oliviera, I.M., Fernandez, F.A.N., Rodriguez, S., Sousa, P.H.M, Maia, G.A. and Figueirend, R.W . 2006. Modeling and optimisation of osmotic dehydration of banana followed by air drying, Journal of Food Engineering 29: 400-413.

Poryan, D.R. and Pilgrim, F.J. 1957. The Methology of sensory testing, IFST Sykp. Pittsburg, U.S.A. Food Technology Champaign II. pp. 9-14.

Reza, M.S., Bapary, M.A.J., Islam, M.N. and Kamal, M. 2009. Optimization of marine fish drying using solar tunnel dryer. Journal of Food Processing and Preservation 33: 47-59.

Reza, M.S., Bapary, M.A.J., Azimuddin, K.M., Nurullah, M. and Kamal, M. 2005. Studies on the traditional drying activities of commercially important marine fishes of Bangladesh. Pakistan Journal of Biological Sciences, 8(9): 1303-1310.

Sultana, S. 2008. Drying performance of solar tunnel and rotating dryers for producing high quality marine dried fish products. MS Thesis, Department of Fisheries Technology, Bangladesh Agricultural University, Mymensingh, Bangladesh. 32 pp.

Del Valle, F.R. and Nickerson, J.T.R. 1968. Salting and Drying Fish 3: Diffusion of Water. Journal of Food Science 33: $499-503$. 